\title{
Stromal Corneal Edema
}

National Cancer Institute

\section{Source}

National Cancer Institute. Stromal Corneal Edema. NCI Thesaurus. Code C50859.

Fluid from the aqueous humor enters the corneal stroma and causes swelling. 